3

4

5

6

7

8

9 (1)

\title{
Dietary nano-chromium tri-picolinate increases feed intake and decreases plasma cortisol in finisher gilts during summer
}

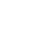

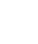

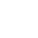

A. T. Hung ${ }^{1}$, B. J. Leury ${ }^{1}$, M. A. Sabin ${ }^{2}$, C. L. Collins ${ }^{3}$ and F. R. Dunshea ${ }^{1 *}$

(1)

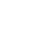

${ }^{1}$ Melbourne School of Land and Environment, The University of Melbourne, Parkville, VIC 3010, Australia

${ }^{2}$ Murdoch Children's Research Institute, The University of Melbourne, Parkville, VIC 3010, Australia

${ }^{3}$ Rivalea (Australia) Pty Ltd, Corowa, NSW 2646, Australia

*Corresponding author: Professor F. R. Dunshea, Melbourne School of Land and Environment, The University of Melbourne, Parkville, VIC 3010, Australia, Tel) + 61-3-83447124, Fax) 61-3-83445037, E-mail: fdunshea@unimelb.edu.au 9

Key words: Chromium, Nanotechnology, feed intake, cortisol, pigs, heat stress 


\section{Abstract}

24 Chromium $(\mathrm{Cr})$ is an essential mineral element and has been used in pig diets to

25 improve growth performance, insulin sensitivity, immune response, carcase traits and

26 to reduce heat or other stress responses. The aims of this study were to determine the

27 impact of nano-sized chromium tripicolinate (nCrPic) on growth performance, feed

28 efficiency and carcase characteristics of finisher gilts during the summer period. A

29 total of sixty finisher Large White $\mathrm{x}$ Landrace gilts were stratified on initial weight

30 and then within strata randomly allocated into two treatment groups in three replicates

31 during mid-summer for 28 days. All pigs were housed in individual pens and had $a d$

32 libitum access to feed and water. Pigs were fed either a control finisher diet (wheat

33 based diet containing 13.8 MJ DE/kg and $0.56 \mathrm{~g}$ available lysine/MJ DE) or a control

34 diet containing $400 \mathrm{ppb} \mathrm{Cr}$ as nCrPic. Dietary nCrPic supplementation increased feed

35 intake by $6 \%$ over the entire study $(\mathrm{P}=0.05)$. In particular, dietary $\mathrm{nCrPic}$ increased

36 ADFI by $8 \%(\mathrm{P}=0.02)$ during the final 2 weeks of the study. Moreover, dietary nCrPic

37 tended to improve ADF over the entire study $(\mathrm{P}=0.09)$. However, there were no

38 significant effects of $\mathrm{nCrPic}$ on $\mathrm{FCR}$, final weight, hot standard carcase weight

39 (HCWT), P2 depth or dressing percentage. Plasma cortisol was decreased by $25 \%$

$40(\mathrm{P}=0.06)$ by dietary nCrPic supplementation. However, there were no effects of

$41 \mathrm{nCrPic}$ on plasma glucose, insulin and nonesterified fatty acids (NEFA), might

42 because of the higher feed intake. In conclusion, this study demonstrates that dietary

$43 \mathrm{nCrPic}$ supplementation at $400 \mathrm{ppb}$ can increase feed intake in finisher gilts during 
44 mid-summer suggesting that $\mathrm{nCrPic}$ can ameliorate some of the negative effects of 45 heat stress in pigs, possibly via decreased of circulating cortisol.

\section{Introduction}

48 A hot environment has negative impacts on production, reproduction, metabolism,

49 health status and immune response. Despite advances in the construction and design

50 of animal housing facilities and cooling technologies (Armstrong. 1994), animal

51 production can still be severely affected by heat stress (St-Pierre et al. 2003). The

52 heat-induced economic burden is due to a combination of increased mortality and

53 decreased growth performance, nutrient utilization, sow performance, and carcase

54 quality (St-Pierre et al. 2003). Consequently, climate change threatens the global

55 protein supply chain and may decrease the competitiveness of the pig industry

56 (Godfray et al. 2010). Heat-stressed animals decrease their feed intake, presumably in

57 an effort to reduce heat production and the resultant reduced nutrient intake is

58 responsible, at least in part, for the reduction in performance (Quiniou et al. 2000).

59 Finishing pigs are particularly susceptible to high temperatures due to their decreased

60 evaporative critical temperature and the high stocking density often found during this

61 phase of production (Kouba et al. 2001; Spencer et al. 2005).

62

$63 \mathrm{Cr}$ is an essential mineral and has been included in pig diets to improve growth

64 performance, insulin sensitivity, immune response, carcase traits and to reduce the 
65 impact of heat or other stressors (Hung et al. 2010). The interest in $\mathrm{Cr}$

66 supplementation during the finisher phase of pig production is primarily for its

67 potential impact to improve body composition, and to a lesser extent, for any

68 associated improvement in performance. However, the effect of $\mathrm{Cr}$ on growth

69 performance is inconsistent. For example, $\mathrm{Cr}$ supplementation studies conducted with

70 pigs have been shown to either result in improve (Page et al. 1993; Lindemann et al.

71 1995; Mooney and Cromwell, 1995, 1997), or have no effect (Evock-Clover et al.

72 1993; Xi et al. 2001; Matthews et al. 2003) on growth performance. A meta-analysis

73 conducted by Sales and Jančík (2011) reported that dietary Cr can increase average

74 daily gain (ADG) and feed efficiency (FCR), whereas there is no effect on average

75 daily feed intake (ADFI). At least some of the variation in response to $\mathrm{Cr}$ may be

76 related to the low and variable digestion, absorption and availability of $\mathrm{Cr}$ and there is

77 potential to improve this by producing nano- or micro-sized Cr. Lien et al. (2009)

78 reported that nano-sized $\mathrm{Cr}$ had 1.66 fold greater digestibility than normal size.

79 Gonzales-Eguia et al. (2009) also indicated that availability of copper is higher in

80 nano sized particle copper. Moreover, the study reported by Hung et al. (2014) also

81 found benefits of $\mathrm{Cr}$ inclusion in finisher diets, particularly when $\mathrm{CrPic}$ was ground to

82 a small particle size (nCrPic). Carcase P2 was decreased and longissimus muscle area

83 increased when gilts were fed a high-fat finisher diet supplemented with $400 \mathrm{ppb}$

84 nCrPic. A meta-analysis conducted by Hung et al. (2010) reported that dietary nCrPic

85 can increase loin muscle area and decreased fat depth to a greater extent than normal 
(ca. $0.5 \mathrm{~mm}$ ) sized CrPic. Previous studies have demonstrated the potential of $\mathrm{Cr}$ to reduce the negative effects of heat stress in broiler and layer poultry (Sahin et al. 2002a; Sahin et al. 2002b; Al-Saiady et al. 2004; 2005). In a rodent model, dietary nCr improved growth rate and feed efficiency in heat-stressed rats (Zha et al. 2009). The risk of high rigour temperature of beef carcasses increases with increasing insulin resistance (Warner et al. 2014) and it has been proposed that the ability of dietary $\mathrm{Cr}$ to improve insulin sensitivity may provide a means of ameliorating heat shortening in beef cattle (DiGiacomo et al. 2014) and heat stress in dairy cattle (Dunshea et al. 2013). However, there are no studies investigating the effect of $\mathrm{Cr}$ on heat stress or during hot condition in finishing pigs. Therefore, this study was conducted the impact of nCrPic on growth performance, feed efficiency and carcase characteristics of female finisher pigs during summer.

\section{Methods and Materials}

\section{Animals and treatments}

All animal procedures were approved by the Rivalea Pty Ltd. Corowa, NSW, Australia (Rivalea Australia) Animal Ethics Committee. Sixty Large White $\times$ Landrace cross breed finishing gilts (PrimeGro ${ }^{\mathrm{TM}}$ Genetics) from the Research and Development facility at Rivalea Australia were selected at approximately 17 weeks of age (initial live weight $67.7 \pm 0.46 \mathrm{~kg}$, mean \pm standard error $(\mathrm{SE}), \mathrm{kg}$ ). Pigs were stratified on weight and then within strata randomly allocated into two treatments in 
107 three replicates during the mid-summer (January-February, 2011). The average 108 maximum temperature during the experiment was $29.7{ }^{\circ} \mathrm{C}$, with a total of 24 days 109 where the daily maximum temperature was above $28{ }^{\circ} \mathrm{C}$. All pigs were housed in 110 individual pens in a shed with no additional cooling and had ad libitum access to feed

111 and water. The experiment included one-week acclimatization and 28 days 112 experimental period. During the acclimatization period, pigs were fed with 113 commercial standard grower diet (Rivalea Australia). During experimental period, 114 pigs were fed a control finisher diet (wheat based diet containing $13.9 \mathrm{MJ}$ digestible 115 energy (DE)/kg and 0. $52 \mathrm{~g}$ available lysine/MJ DE) or control diet plus $400 \mathrm{ppb} \mathrm{Cr}$ as 116 nCrPic (Table1). The nCrPic was prepared according to our previous study (Hung et 117 al. 2014). Briefly, the raw CrPic material was ground and then passed through 118 appropriate sized end-plates sieves to collect nCrPic.

Husbandry and management

121 Pigs were housed in individual pens in the Rivalea Research and Development boar

122 test facility. Individual live weights were obtained at day 0,14 and 28 of the study.

123 Feed intake was recorded weekly throughout the experimental period as estimated by

124 feed disappearance. In addition back fat thickness was measured via real time 125 ultrasound (Pork Scan Pty. Ltd. Australia) at the P2 site (65 $\mathrm{mm}$ from the midline over 126 the final rib) and leg (60 $\mathrm{mm}$ to the right of the midline base of the tail) on day 0 and 127 28. At the end of experiment, pigs were slaughtered at a commercial abattoir to 
128 determine hot carcase weight (HCWT) and dressing percentage. HCWT was 129 standardized as head on (including tongue); kidneys removed (kidney fat remaining), 130 fore and hind trotters on.

131

132 Blood sampling

133 Pigs were fasted for 16 hours prior to blood collection. Fifteen animals were selected 134 randomly from each treatment (five pigs/ replicate) for blood collection on day 27. 135 After collection of blood, the samples were placed on ice for $1 \mathrm{~h}$, and then centrifuged 136 for $15 \mathrm{~min}$ at $1,500 \times \mathrm{g}$. Plasma was collected and frozen $\left(-20^{\circ} \mathrm{C}\right)$ until subsequent 137 analysis for glucose, insulin, and NEFA concentrations. Plasma insulin (Millipore 138 Corporation, USA) and cortisol (Diagnostica, Finland) levels were used commercial 139 kit and determined by radioimmunoassay. Plasma glucose (Thermo Fisher Scientific 140 Inc. USA), and NEFA (NEFA-C kit, Wako Chemical Industries Ltd, Osake, Japan) 141 concentrations were determined by enzymatic colorimetric procedures.

143 Statistical analyses

144 Data were analysed by analysis of variance using GENESTAT release 11.1 (VSN

145 International Ltd. UK). Initial live weight was used as a covariate for ADG, final live 146 weight and HCWT and initial P2 were used as covariate for final P2. The quantitative 147 insulin sensitivity check index (QUICKI baseline) was calculated using the formula, 148 QUICKI=1/ (log fasting insulin, $\mu \mathrm{U} / \mathrm{mL}+\log$ fasting glucose, mg/dL) (Katz et al., 
149 2000). Normal QUICKI values are around 0.45 with values closer to 0.30 indicating 150 insulin resistance, an increase in QUICKI is associated with increased insulin 151 sensitivity (Katz et al., 2000). The homeostatic model assessment (HOMA) was 152 calculated using the formula, $\mathrm{HOMA}=$ (fasting insulin $\times$ fasting glucose) $/ 22.5$ (Katz 153 et al., 2000). A decrease in HOMA is associated with reduced insulin resistance.

154

155 Results

156 Growth performance

157 While there were no significant effect of $\mathrm{nCrPic}$ on $\mathrm{ADFI}$ during the first 14 days 158 (2.31 vs $2.37 \mathrm{~kg} /$ day for control and $\mathrm{nCrPic}$ diet, respectively, $\mathrm{P}=0.43$ ), as the study 159 progressed dietary $\mathrm{nCrPic}$ increased ADFI such that during the final 2 weeks of the 160 study ADFI was 9\% higher in pigs supplemented with dietary nCrPic (2.53 vs 2.75 $161 \mathrm{~kg} /$ day, respectively, $\mathrm{P}=0.02$ ) (Table 2). Consequently, ADFI over the entire study was 162 increased by $6 \%$ by dietary $\mathrm{nCrPic}(2.42$ vs $2.56 \mathrm{~kg} /$ day, respectively, $\mathrm{P}=0.05)$. There 163 were no significant effects of nCrPic on ADG during the first 14 days (0.88 vs 0.95

$164 \mathrm{~kg} /$ day, respectively, $\mathrm{P}=0.12$ ) or over the period from 14 to 28 days (1.00 vs 1.02

$165 \mathrm{~kg} /$ day, respectively, $\mathrm{P}=0.59)$. However, ADG tended to be increased by $5 \%$ dietary $166 \mathrm{nCrPic}$ when measured over the entire study (0.94 vs $0.99 \mathrm{~kg} / \mathrm{day}, \mathrm{P}=0.09$ ). Dietary 167 nCrPic had no effect on FCR in the current study (Table 2). 
170 In line with effects on ADFI and ADG, dietary nCrPic tended to increase live weight

171 at the completion of the study (94.0 vs $95.4 \mathrm{~kg}$ respectively, $\mathrm{P}=0.09$ ) (Table 3).

172 However, dietary nCrPic did not significantly alter HSCW (70.2 vs $71.1 \mathrm{~kg}, \mathrm{P}=0.14$ )

173 or dressing percentage ( 74.4 vs $74.4 \%, \mathrm{P}=0.71)$. The depth of back fat at the $\mathrm{P} 2$ site

$174(\mathrm{P}=0.94)$ or over the leg $(\mathrm{P}=0.45)$ at the end of the study did not differ with treatment

175 (Table 3).

176

177 Plasma metabolites

178 Dietary nCrPic tended to decrease cortisol level (17.8 vs $15.2 \mathrm{nM} / \mathrm{L}$, for control and

179 nCrPic diet, respectively, $\mathrm{P}=0.06$ ) (Table 4). However, there was no effect of dietary

180 nCrPic on plasma glucose $(\mathrm{P}=0.48)$, insulin $(\mathrm{P}=0.96)$, NEFA $(\mathrm{P}=0.69)$ concentration

181 or the HOMA $(\mathrm{P}=0.91)$ and QUICKI $(\mathrm{P}=0.98)$ measures on day 27 of the study

182 (Table 4).

183

184 Discussion

185 Thermal stress reduces animal productivity and decreases ADFI in farm animals and

186 therefore it is desirable to develop nutritional strategies, likely based on physiological

187 and/or metabolic adaptations to help maintain pig performance during summer. The

188 major finding from the present study was that dietary $\mathrm{nCrPic}$ supplementation during

189 a hot summer period can increase ADFI with resultant improvements in ADG and

190 slaughter weigh. High ambient temperatures can reduce the efficiency and 
191 profitability in pig production (Nardone et al. 2010) with pigs being particularly 192 susceptible during the late finishing phase due to their lower evaporative critical 193 temperature. Evaporative heat loss from the respiratory tract is the major mechanism 194 by which pigs dissipate heat (Giles et al. 1988; Marai et al. 2007). When pigs reach 195 the point where evaporative heat loss from the respiratory tract and skin is at a 196 maximum, the upper critical temperature is also reached (Giles et al. 1988). Beyond 197 this point, pigs will voluntarily reduce ADFI in order to reduce their heat production. 198 For example, Le Bellego et al. (2002) reported that pigs reduced ADFI by $55 \mathrm{~g}$ per ${ }^{\circ} \mathrm{C}$ 199 above $22{ }^{\circ} \mathrm{C}$ and ceased eating when their body temperature reached about $41.3{ }^{\circ} \mathrm{C}$. 200 The reduction in ADFI during high ambient temperatures was more pronounced in 201 pigs during the finishing phase than during the growing phase $\left(78\right.$ vs $35 \mathrm{~g} /$ day per ${ }^{\circ} \mathrm{C}$ 202 above $22{ }^{\circ} \mathrm{C}$ for finishing phase and growing phase pig, respectively) (Le Bellego et al. 203 2002). This is because the upper critical temperature decreases with the increasing of 204 live weight (Giles et al. 1988; Quiniou et al. 2000) which may explain why the 205 improvement in ADFI became more pronounced as the present study progressed. An 206 improvement in growth performance, after CrPic supplementation during heat stress, 207 also been observed in poultry. For example, dietary supplementation of CrPic 208 ameliorated the detrimental effects of heat stress on growth and egg production (Sahin 209 et al. 2002a; Sahin et al. 2005). Also, supplementation of CrPic at levels from 200 to $2101200 \mu \mathrm{g} / \mathrm{kg}$ linearly increased feed intake, live weight gain, and egg production rate of 211 laying quail reared under heat stress condition (Sahin et al. 2002a). Finally, dietary Cr 
212 Yeast (4 g/head per day) increased feed intake in Holstein cows under heat stress

213 (Al-Saiady et al. 2004). These data suggested that dietary Cr may be able to use in

214 farm animals to alleviate the negative effects of high environment temperature.

215

216 The results from our previous study (Hung et al. 2014), in conjunction with other

217 literatures (Wang and $\mathrm{Xu}, 2004$; Wang et al. 2007; Wang et al. 2009a) suggested that

218 dietary nano $\mathrm{Cr}$ could reduce the body fat content in pigs. However, in the present

219 study, there was no effect of dietary nCrPic on P2 backfat and leg fat depth of pigs.

220 Verstegen et al. (1973) indicated that pigs reared in hot environment typically yield

221 carcasses with a higher percent lean. The reduction in fat content of pigs under heat

222 stress was due to a reduction in total energy intake in the hot environment. Dietary

$223 \mathrm{nCrPic}$ increased feed intake during the day 14 to 28 in this study suggested that pigs

224 feed with nCrPic increased total energy intake in the late finishing period compared

225 with the control group. Increased energy intake without changed the P2 back fat and

226 leg fat depth implied that pigs fed with $\mathrm{nCrPic}$ had better efficiency to metabolized fat.

227 It should be noted that, by commercial standards, the pigs in the current study were

228 already very lean and had a low P2 backfat.

229

230 Heat stress likely affects many aspects of metabolism, including alterations in

231 substrate uptake and utilization, much of which is not yet fully understood. Metabolic

232 adaptations during high ambient temperatures likely occur in order to increase 
233 survival probability. Denbow et al. (1986) reported insulin concentration are lower in

234 summer than in winter and spring in Holstein cattle, possibly as a result of reduced

235 feed intake. In lactating sows, plasma insulin was lower during high ambient

236 temperature compared to sows housed under thermo-neutral conditions despite similar

237 glucose concentrations (de Bragança and Prunier, 1999). Conversely, Achmadi et al.

238 (1993) reported that heat-exposer had no effect on fasting insulin level. Circulating

239 glucose concentrations were increased in pigs (Prunier et al. 1997) and cattle

240 (Denbow et al. 1986), but decreased in sheep (Achmadi et al. 1993) and cattle

241 (Shwartz et al. 2009; Wheelock et al. 2010), and unchanged in pigs in another study

242 (de Bragança and Prunier, 1999) under hot conditions. Heat exposure increased

243 plasma NEFA in sheep (Sevi et al. 2002), but decreased NEFA in lactating cattle (Itoh

244 et al. 1998; Shwartz et al. 2009; Wheelock et al. 2010). These differences between

245 basal hormone and metabolite concentrations may relate to differences in

246 experimental conditions such as ambient temperature and feeding manner,

247 physiological status, and animal species. Importantly, it worth to understand the

248 degree to which feed intake is impacted by high ambient temperatures as reduced feed

249 intake generally results in increased NEFA and decreased glucose and insulin. Also,

250 insulin resistance increase with fatness and the rate of fat deposition in pigs (Dunshea

251 and Cox et al. 2008). There in now increasing evidence that insulin resistant and

252 diabetic individuals suffer from thermal intolerance, exhibiting an inability to control

253 body temperature (Ohtsuke et al. 1995). In part this is because skin blood flow and 
254 skin thickness are reduced in diabetic individuals (Forst et al. 2006), thereby reducing 255 the ability of thermoregulation. If dietary nCrPic can improve insulin sensitivity then 256 it may explain why feed intake is improved with dietary nCrPic during summer and 257 that the effect was greater during latter part of the study when the pigs would be fatter.

259 Chromium is a trace mineral that is widely distributed throughout the body, being 260 necessary for maintenance of insulin function and glucose uptake by insulin-sensitive 261 tissues (Anderson et al. 1985). However, the effects of dietary $\mathrm{Cr}$ on fasting glucose 262 concentrations in pigs are inconsistent. Some studies reported that dietary $\mathrm{Cr}$ 263 significantly reduces fasting glucose (Lien et al. 2001; Wang et al. 2001; Wang et al. 264 2009b), whereas others reported no effect (Amoikon et al. 1995; Matthews et al. 265 2001). Amoikon et al. (1995) reported that CrPic increased insulin sensitivity as 266 assessed by increased glucose clearance rate and decreased glucose half-life during a 267 glucose tolerance test and insulin challenge test in pigs. It is reported that CrPic can 268 increase the rate of insulin internalizations and uptake of glucose into skeletal muscle 269 cells (Evans and Bowman, 1992). Under heat stress condition, dietary CrPic 270 decreased glucose level in quails (Quiniou et al. 2000) and broiler chickens (Samanta 271 et al. 2008) indicating improved glucose clearance and insulin sensitivity. Zha et al. 272 (2009) indicated that heat-stressed male Sprague-Dawley rats fed with nano-Cr had 273 lower insulin. However, supplementation of CrPic linearly increased insulin 274 concentration at levels from 200 to $1200 \mu \mathrm{g} / \mathrm{kg}$ (Sahin et al. 2002a). Yari et al. (2010) 
275 suggested that an improvement in peripheral insulin sensitivity as evidence by an

276 intravenous GTT revealed linear reductions in AUC of insulin during 0-90 and 0-120

277 minute after glucose infusion in calf fed with Cr-L-methionine in summer. As

278 reported by Hung et al. (2014), dietary increased insulin sensitivity as indicated by a

279 decrease in both fasting insulin and HOMA, and an increase in QUICKI. In the

280 present study, however, dietary $\mathrm{nCrPic}$ had no significant effect on glucose, insulin,

281 NEFA, HOMA, and QUICKI in finisher gilts during summer. The lack of effect on

282 these measures of insulin sensitivity and intermediary metabolism may be due to the

283 increase in feed intake over the latter phase of the study which would have the effect

284 of increasing plasma glucose and insulin, and lowering plasma NEFA (ie. opposite

285 effects of improving insulin sensitivity in the face of no change in feed intake).

286

287 Circulating cortisol concentration was tended to decrease by dietary nCrPic

288 supplementation. A reduction in plasma cortisol is a classic metabolic consequence of

$289 \mathrm{Cr}$ in farm animals suggesting there was a reduction in stress, especially when animals

290 are challenged with stressors such as a thermal-stress. For example, in heat-stressed

291 broiler chickens, dietary CrPic decreased serum cortisol concentration (Samanta et al.

292 2008). While, Sahin et al. (2002a) reported that dietary CrPic linearly decreased

293 serum corticosterone concentration across the range of $200-1200 \mu \mathrm{g} / \mathrm{kg}$ in

294 heat-stressed laying quail. A stress-induced increase in circulating cortisol may

295 contribute to increase hepatic gluconeogenesis and heat production, thereby escalating 
296 the heat load of the animal (McDonald et al. 2011). Farm animals tend to reduce feed

297 intake to adapt to high environment temperature (Nardone et al. 2010). Zha et al.

298 (2009) suggested that nCrPic can balance circulating cortisol and insulin level to

299 maintaining homeostasis. The anorexigenic actions of cortisol can mediated via

300 reducing circulating ghrelin levels as well as GHSR1a-LR (biologically active ghrelin

301 receptor) expression and/or suppressing neuropeptide Y expression (Janzen et al.,

302 2013). These data suggest that the improvement in feed intake in dietary nCrPic

303 supplemented pigs may be via the decreased cortisol secretion. Alternatively, the

304 reduction in cortisol in pigs supplemented with dietary $\mathrm{nCrPic}$ may mean they are

305 under less stress.

306

307 Conclusion

308 These data clearly show that dietary nCrPic supplementation at $400 \mathrm{ppb}$ can increase

309 feed intake and tended to increase ADG in finisher gilts during mid-summer

310 suggesting that $\mathrm{nCrPic}$ can ameliorate some of the negative effects of heat stress in

311 pigs possibly via decreased circulating cortisol. However, this study failed to detect

312 any effects of dietary nCrPic on the levels of plasma glucose, insulin, NEFA, HOMA

313 and QUICKI under these conditions, might because of the increased feed intake.

314 Further studies are required to examine the growth performance and physiological

315 response in animal under heat stress condition.

316 
321 The authors declare that they have no conflict of interest 322 


\section{Reference}

Achmadi, J., Yanagisawa, T., Sano, H. and Terashima, Y., 1993. Pancreatic insulin secretory response and insulin action in heat-exposed sheep given a concentrate or roughage diet, Domestic Animal Endocrinology, 10, 279-287.

Al-Saiady, M. Y., Al-Shaikh, M. A., Al-Mufarrej, S. I., Al-Showeimi, T. A., Mogawer, H. H. and Dirrar, A., 2004. Effect of chelated chromium supplementation on lactation performance and blood parameters of Holstein cows under heat stress, Animal Feed Science and Technology, 117, 223-233.

Amoikon, E. K., Fernandez, J. M., Southern, L. L., Thompson, D. L., Ward, T. L. Jr. and Olcott, B. M., 1995. Effect of chromium tripicolinate on growth, glucose tolerance, insulin sensitivity, plasma metabolites, and growth hormone in pigs, Journal of Animal Science, 73, 1123-1130.

Anderson, R. A., Bryden, N. A. and Polansky, M. M., 1985. Serum chromium of human subjects: effects of chromium supplementation and glucose, The American journal of clinical nutrition, 41, 571-577.

Armstrong, D. V., 1994. Heat Stress Interaction with Shade and Cooling, Journal of Dairy Science, 77, 2044-2050.

de Bragança, M. M. and Prunier, A., 1999. Effects of low feed intake and hot environment on plasma profiles of glucose, nonesterified fatty acids, insulin, glucagon, and IGF-I in lactating sows, Domestic Animal Endocrinology, 16, 89-101.

Denbow, C. J., Perera, K. S., Gwazdauskas, F. C., Akers, R. M., Pearson, R. E. and McGilliard, M. L., 1986. Effect of Season and Stage of Lactation on Plasma Insulin and Glucose Following Glucose Injection in Holstein Cattle, Journal of Dairy Science, 69, 211-216.

DiGiacomo, K., Leury, B. J. and Dunshea, F. R., 2014. Possible metabolic causes of heat shortening in cattle and potential strategies base on these mechanisms, Animal Production Science, 54, 430-443.

Dunshea, F. R., Leury, B. J., Fahri, F., DiGiacomo, K., Hung, A., Chauhan, S., Clarke, I. J., Collier, R., Little, S., Baumgard, L. and Gaughan, J. B., 2013. Amelioration of thermal stress impacts in dairy cows, Animal Production Science, 53, 965-975.

Evans, G. W. and Bowman, T. D., 1992. Chromium picolinate increases membrane fluidity and rate of insulin internalization, Journal of inorganic biochemistry, 46, 243-250.

Evock-Clover, C. M., Polansky, M. M., Anderson, R. A. and Steele, N. C., 1993. 
Dietary chromium supplementation with or without somatotropin treatment alters serum hormones and metabolites in growing pigs without affecting growth performance, The Journal of nutrition, 123, 1504-1512.

Giles, L. R., Dettmann, E. B. and Lowe, R. F., 1988. Influence of diurnally fluctuating high temperature on growth and energy retention of growing pigs, Animal production, 47, 467-474.

Godfray, H. C., Crute, I. R., Haddad, L., Lawrence, D., Muir, J. F., Nisbett, N., Pretty, J., Robinson, S., Toulmin, C. and Whiteley, R., 2010. The future of the global food system, Philosophical Transactions of the Royal Society of London, 365, 2769-2777.

Gonzales-Eguia, A. Fu, C. M., Lu, F. Y. and Lien, T. F., 2009. Effects of nanocopper on copper availablity and nutrients digestibility, growth performance and serum traits of piglets. 126:122-129.

Hung, T. Y., Leury, B. J., Lien, T. F., Lu, J. J. and Dunshea, F. R., 2010. Potential of nano-chromium to improve body composition and performance of Pigs. In: Proceeding of the14th AAAP Animal Science Congress, Pingtong, Taiwan. 108-112.

Hung, A. T., Leury, B. J., Sabin, M. A., Lien, T. F. and Dunshea, F. R., 2014. Dietary chromium picolinate of varying particle size improves carcass characteristics and insulin sensitivity in finishing pigd fed low and high fat diet, Animal Production Science, (Published online)

Itoh, F., Obara, Y., Rose, M. T., Fuse, H. and Hashimoto, H., 1998. Insulin and glucagon secretion in lactating cows during heat exposure, Journal of Animal Science, 76, 2182-2189.

Janzen, W. J., Duncan, C. A. and Riley, L. G., 2012. Cortisol treatment reduces ghrelin signaling and food intake in tilapia, Oreochromis mossambicus. Domestic Animal Endocrinoligy. 43:251-259.

Katz, A., Nambi, S.S., Mather, K., Baron, A. D., Follmann, D. A., Sullivan, G. and Quon, M. J., 2000. Quantitative insulin sensitivity check index: a simple, accurate method for assessing insulin sensitivity in humans, The Journal of Clinical Endocrinology \& Metabolism, 85, 2402-2410.

Kim, B. G., Lindemann, M. D. and Cromwell, G. L., 2009. The effects of dietary chromium(III) picolinate on growth performance, blood measurements, and respiratory rate in pigs kept in high and low ambient temperature, Journal of Animal Science, 87, 1695-1704.

Kouba, M., Hermier, D. and Le Dividich, J., 2001. Influence of a high ambient temperature on lipid metabolism in the growing pig, Journal of Animal Science, 
79, 81-87.

Le Bellego, L., van Milgen, J. and Noblet, J., 2002. Effect of high temperature and low-protein diets on the performance of growing-finishing pigs, Journal of Animal Science, 80, 691-701.

Lien, T. F., Wu, C. P., Wang, B. J., Shiao, M. S. and Lu, J. J., 2001. Effect of supplemental levels of chromium picolinate on the growth performance, serum traits, carcass characteristics and lipid metabolism of growing-finishing pigs, Animal Science, 72, 289-296.

Lien, T. F., Yeh, H. S., Lu, F. Y. and Fu, C. M. 2009. Nanoparticles of chromium picolinate enhance chromium digestibility and absorption. Journal of the Science of Food and Agriculture. 89:1164-1167.

Lindemann, M. D., Wood, C. M., Harper, A. F., Kornegay, E. T. and Anderson, R. A., 1995. Dietary chromium picolinate additions improve gain:feed and carcass characteristics in growing-finishing pigs and increase litter size in reproducing sows, Journal of Animal Science, 73, 457-465.

Marai, I. F. M., El-Darawany, A. A., Fadiel, A. and Abdel-Hafez, M. A. M., 2007. Physiological traits as affected by heat stress in sheep--A review, Small Ruminant Research, 71, 1-12.

Matthews, J. O., Higbie, A. D., Southern, L. L., Coombs, D. F., Bidner, T. D. and Odgaard, R. L., 2003. Effect of chromium propionate and metabolizable energy on growth, carcass traits, and pork quality of growing-finishing pigs, Journal of Animal Science, 81, 191-196.

Matthews, J. O., Southern, L. L., Fernandez, J. M., Pontif, J. E., Bidner, T. D. and Odgaard, R. L., 2001. Effect of chromium picolinate and chromium propionate on glucose and insulin kinetics of growing barrows and on growth and carcass traits of growing-finishing barrows, Journal of Animal Science, 79, 2172-2178.

McDonald, P., Edwards, R. A., Greenhalgh, J. F. D. and Morgan, C. A., 2011. Animal nutrition 7th ed. (Pearson, Harlow).

Mooney, K. W. and Cromwell, G. L., 1995. Effects of dietary chromium picolinate supplementation on growth, carcass characteristics, and accretion rates of carcass tissues in growing-finishing swine, Journal of Animal Science, 73, 3351-3357.

Mooney, K. W. and Cromwell, G. L., 1997. Efficacy of chromium picolinate and chromium chloride as potential carcass modifiers in swine, Journal of Animal Science, 75, 2661-2671.

Nardone, A., Ronchi, B., Lacetera, N., Ranieri, M. S. and Bernabucci, U., 2010. Effects of climate changes on animal production and sustainability of livestock systems, 
Livestock Science, 130, 57-69.

Page, T. G., Southern, L. L., Ward, T. L. and Thompson, D. L. Jr., 1993. Effect of chromium picolinate on growth and serum and carcass traits of growing-finishing pigs, Journal of Animal Science, 71, 656-662.

Prunier, A., de Bragança, M. M. and Le Dividich, J., 1997. Influence of high ambient temperature on performance of reproductive sows, Livestock Production Science, 52, 123-133.

Quiniou, N., Dubois, S. and Noblet, J., 2000. Voluntary feed intake and feeding behaviour of group-housed growing pigs are affected by ambient temperature and body weight, Livestock Production Science, 63, 245-253.

Sahin, K., Ozbey, O., Onderci, M., Cikim, G. and Aysondu, M. H., 2002. Chromium Supplementation Can Alleviate Negative Effects of Heat Stress on Egg Production, Egg Quality and Some Serum Metabolites of Laying Japanese Quail, The Journal of nutrition, 132, 1265-1268.

Sahin, K., Sahin, N., Onderci, M., Gursu, F. and Cikim, G., 2002. Optimal dietary concentration of chromium for alleviating the effect of heat stress on growth, carcass qualities, and some serum metabolites of broiler chickens, Bioligical Trace Element Research, 89, 53-64.

Sahin, N., Sahin, K., Onderci, M., Gursu, M. F., Cikim, G., Vijaya, J. and Kucuk, O., 2005. Chromium picolinate, rather than biotin, alleviates performance and metabolic parameters in heat-stressed quail, British Poultry Science, 46, 457-463.

Sales, J. and Jančík, F., 2011. Effects of dietary chromium supplementation on performance, carcass characteristics, and meat quality of growing-finishing swine: A meta-analysis, Journal of Animal Science, 89, 4054-4067.

Samanta, S., Haldar, S. and Ghosh, T. K., 2008. Production and carcase traits in broiler chickens given diets supplemented with inorganic trivalent chromium and an organic acid blend, British Poultry Science, 49, 155-163.

Sevi, A., Rotunno, T., Di Caterina, R. and Muscio, A., 2002. Fatty acid composition of ewe milk as affected by solar radiation and high ambient temperature, Journal of Dairy Research, 69, 181-194.

Shwartz, G., Rhoads, M. L., VanBaale, M. J., Rhoads, R. P. and Baumgard, L. H., 2009. Effects of a supplemental yeast culture on heat-stressed lactating Holstein cows, Journal of Dairy Science, 92, 935-942.

Spencer, J. D., Gaines, A. M., Berg, E. P. and Allee, G. L., 2005. Diet modifications to improve finishing pig growth performance and pork quality attributes during periods of heat stress, Journal of Animal Science, 83, 243-254. 
St-Pierre, N. R., Cobanov, B. and Schnitkey, G., 2003. Economic Losses from Heat Stress by US Livestock Industries, Journal of Dairy Science, 86, 52-77.

Verstegen, M. W., Close, W. H., Start, I. B. and Mount, L. E., 1973. The effects of environmental temperature and plane of nutrition on heat loss, energy retention and deposition of protein and fat in groups of growing pigs, British Journal of Nutrition, 30, 21-35.

Wang, M. Q., He, Y. D., Lindemann, M. D. and Jiang, Z. G., 2009a. Efficacy of Cr (III) supplementation on growth, carcass composition, blood metabolites, and endocrine parameters in finishing pigs, Asian-Australasian Journal of Animal Sciences, 22, 1414-1419.

Wang, M. Q. and Xu, Z. R., 2004. Effect of chromium nanoparticle on growth performance, carcass characteristics, pork quality and tissue chromium in finishing pigs, Asian-Australasian Journal of Animal Sciences, 17, 1118-1122.

Wang, M. Q., Xu, Z. R., Li, W. F. and Jiang, Z. G., 2009b. Effect of chromium nanocomposite supplementation on growth hormone pulsatile secretion and mRNA expression in finishing pigs, Journal of Animal Physiology and Animal Nutrition, 93, 520-525.

Wang, M. Q., Xu, Z. R., Zha, L. Y. and Lindemannc, M. D., 2007. Effects of chromium nanocomposite supplementation on blood metabolites, endocrine parameters and immune traits in finishing pigs, Animal Feed Science and Technology, 139, 69-80.

Wang, S., Sun, C., Kao, Q. and Yu, C., 2001. Effects of chromium and fish oil on insulin resistance and leptin resistance in obese developing rats, Wei Sheng Yan Jiu, 30, 284-286.

Warner, R. D., Dunshea, F. R., Gutzke, D., Lau, J. and Kearnry, G., 2014. Factors influencing the incidence of high rigor temperature in beef carcassed in Australia, Animal Production Science, 54, 363-374.

Wheelock, J. B., Rhoads, R. P., VanBaale, M. J., Sanders, S. R. and Baumgard, L. H., 2010. Effects of heat stress on energetic metabolism in lactating Holstein cows, Journal of Dairy Science, 93, 644-655.

Xi, G., Xu, ZR., Wu, S. H. and Chen, S. J., 2001. Effect of chromium picolinate on growth performance, carcass characteristics, serum metabolites and metabolism of lipid in pigs, Asian-Australasian Journal of Animal Sciences, 14, 258-262.

Yari, M., Nikkhah, A., Alikhani, M., Khorvash, M., Rahmani, H. and Ghorbani, G. R., 2010. Physiological calf responses to increased chromium supply in summer, Journal of Dairy Science, 93, 4111-4120.

Zha, L., Zeng, J., Sun, S., Deng, H., Luo, H. and Li, W., 2009. Chromium(III) 
Nanoparticles Affect Hormone and Immune Responses in Heat-Stressed Rats, Biological Trace Element Research, 129, 157-169. 
Table 1. Ingredient and nutrient composition of experimental diets

\begin{tabular}{lc}
\hline Ingredient & \\
\hline Wheat & 68.46 \\
Millmix & 16.5 \\
Canola meal 36\% & 6.0 \\
Meat meal & 2.6 \\
Water & 1 \\
Porzyme 9310 & 0.02 \\
Natuphos 5000 & 0.01 \\
Tallow-mixer & 3.07 \\
Salt & 0.2 \\
Limstone & 1.5 \\
Lysine-HCl & 0.35 \\
DL-methionine & 0.01 \\
Threonine & 0.11 \\
Copper proteinate Micro & 0.1 \\
Growth Premix a,b & 0.07 \\
\hline Total & 100 \\
\hline Calculated nutrient composition & \\
DE, MJ/kg & 13.9 \\
Fat, \% & 4.9 \\
Crude protein, \% & 16.0 \\
Calcium, \% & 0.89 \\
Available Phosphorus, \% & 0.36 \\
Available lysine/MJ DE & 0.52 \\
\hline${ }^{a}$ Provided the following trace mineral per kilogram of diet: Se, $0.2 \mathrm{mg} ;$ Fe, 60; Mn, 25 \\
mg; Zn, 50 mg; I, 0.2 mg; Cu, 10 mg. \\
b Provided the following vitamins per kilogram of diet: Vitamin A, 2.5 mg; \\
Vitamin D3, 1mg; Vitamin E, 30 mg; Niacin, 10 mg; Ca-D-Pantothenate, 5 mg; \\
Riboflavin, 2 mg; Vitamin B12 (Cyanocobalamin), 5 mg. \\
\end{tabular}


Table 2 Effect of nCrPic on growth performance, feed intake and feed efficiency in finisher gilts during summer

\begin{tabular}{|c|c|c|c|c|}
\hline & Control & nCrPic & $\operatorname{sed}^{\mathrm{a}}$ & P-value \\
\hline \multicolumn{5}{|l|}{ Day 0 to 14} \\
\hline $\mathrm{ADFI}^{\mathrm{b}}, \mathrm{kg} / \mathrm{d}$ & 2.31 & 2.37 & 0.076 & 0.43 \\
\hline $\mathrm{ADG}^{\mathrm{b}}, \mathrm{kg} / \mathrm{d}$ & 0.88 & 0.95 & 0.047 & 0.12 \\
\hline FCR (Feed: gain) & 2.72 & 2.55 & 0.127 & 0.20 \\
\hline \multicolumn{5}{|l|}{ Day 14 to 28} \\
\hline $\mathrm{ADFI}^{\mathrm{b}}, \mathrm{kg} / \mathrm{d}$ & 2.53 & 2.75 & 0.085 & 0.02 \\
\hline $\mathrm{ADG}^{\mathrm{b}}, \mathrm{kg} / \mathrm{d}$ & 0.99 & 1.02 & 0.048 & 0.59 \\
\hline FCR (Feed: gain) & 2.63 & 2.77 & 0.136 & 0.32 \\
\hline \multicolumn{5}{|l|}{ Day 0 to 28} \\
\hline $\mathrm{ADFI}^{\mathrm{b}}, \mathrm{kg} / \mathrm{d}$ & 2.42 & 2.56 & 0.070 & 0.05 \\
\hline $\mathrm{ADG}^{\mathrm{b}}, \mathrm{kg} / \mathrm{d}$ & 0.94 & 0.99 & 0.030 & 0.09 \\
\hline FCR (Feed: gain) & 2.61 & 2.62 & 0.080 & 0.96 \\
\hline
\end{tabular}

${ }^{a}$ Standard error of the difference

b - initial weight used as covariate 
Table 3 Effect of nCrPic on carcass characteristics in finisher gilts during summer

\begin{tabular}{|c|c|c|c|c|}
\hline & Control & $\mathrm{nCrPic}$ & $\operatorname{sed}^{\mathrm{a}}$ & P-value \\
\hline Final weight ${ }^{\mathrm{b}}, \mathrm{kg}$ & 94.0 & 95.4 & 0.83 & 0.09 \\
\hline $\mathrm{HCWT}^{\mathrm{b}}, \mathrm{kg}$ & 70.2 & 71.1 & 0.69 & 0.14 \\
\hline Dressing \% & 74.4 & 74.4 & 0.44 & 0.71 \\
\hline $\mathrm{P} 2$ fat depth ${ }^{\mathrm{c}}, \mathrm{mm}$ & 8.0 & 8.0 & 0.19 & 0.94 \\
\hline Leg fat depth ${ }^{\mathrm{c}}, \mathrm{mm}$ & 9.0 & 9.1 & 0.20 & 0.45 \\
\hline
\end{tabular}

${ }^{\mathrm{a}}$ Standard error of the difference; ${ }^{\mathrm{b}}$ Initial weight used as covariate;

c Initial P2 and HCWT used as covariate 
Table 4 Effect of nCrPic on plasma glucose, insulin, NEFA, HOMA and QUICKI in finisher gilts during summer period

\begin{tabular}{lcccc}
\hline & Control & nCrPic & sed $^{\mathrm{a}}$ & P- value \\
\hline Cortisol nmol/L $^{\mathrm{b}}$ & $1.25(17.8)$ & $1.12(13.2)$ & 0.067 & 0.06 \\
Glucose, mmol/L & 3.91 & 3.98 & 0.09 & 0.48 \\
Insulin, $\mathrm{mU} / \mathrm{L}$ & 11.0 & 11.0 & 0.74 & 0.96 \\
NEFA, $\mu \mathrm{M}$ & 307 & 309 & 6.45 & 0.69 \\
HOMA & 1.91 & 1.93 & 0.174 & 0.91 \\
QUICKI & 0.62 & 0.62 & 0.017 & 0.98 \\
\hline
\end{tabular}

${ }^{\text {a }}$ Standard error of the difference

${ }^{b}$ Data were log-transformed before analyses due to heterogeneity of variances. Values in parentheses are the geometric mean. 